\title{
El estudio de la recepción televisiva desde la perspectiva de la ciudadanía organizada
}

\author{
Gloria RosiQue Cedillo \\ Universidad Carlos III de Madrid \\ grosique@hum.uc3m.es
}

\begin{abstract}
Resumen
Considerando el actual contexto audiovisual convergente con las nuevas tecnologías y el nuevo papel de los usuarios de los medios, el determinar en qué medida estos actores de manera organizada afectan o pueden llegar a influir en el desarrollo de la televisión, comienza a convertirse en una necesidad inherente en el campo de la investigación de audiencias en la relación sociedad-medios, bajo el paradigma del nuevo modelo de comunicación multidireccional.

Por tanto, el presente artículo se propone llevar a cabo una revisión bibliográfica en las bases de datos de revistas españolas más importantes en el campo de la comunicación, con el objetivo de identificar la cantidad de producción científica desarrollada en el ámbito de la recepción televisiva, desde la perspectiva de la ciudadanía organizada y su incidencia en la televisión.
\end{abstract}

Palabras clave: Ciudadanos, Telespectadores, Teoría, Recepción televisiva, Capital social.

\section{The study of TV reception from the perspective of organized citizenship}

\begin{abstract}
Considering the present audiovisual context convergent with new technologies and the new role of the media users, it is important to determine to what extent the organized media users affect or can get to influence in the development of the television. This question begins to become in an inherent necessity in the field of the media investigation in the relation "society-mass media", regarding to the paradigm of the new communication multidirectional model.

Therefore, this article proposes to carry out a bibliographical revision in the most important Spanish databases in the communication area, with the aim of identify the amount of scientific production developed in the field of television reception, from the perspective of organized citizens and their impact on television.
\end{abstract}

Key words: Citizens, TV Viewers, Theory, TV Reception, Social Capital.

Referencia normalizada:

Rosique Cedillo, G. (2013) El estudio de la recepción televisiva desde la perspectiva de la ciudadanía organizada. Historia y Comunicación Social. Vol. 18. № Especial Diciembre. Págs. 213-224.

Sumario: 1. Introducción. 1.1 Metodología 2. Aproximaciones y antecedentes teóricos sobre la recepción televisiva. 2.1. El cambio de paradigma en la investigación de las audiencias de televisión 3. Análisis de las publicaciones científicas en bases de datos españolas. 4. Conclusiones. 5. Referencias bibliográficas. 


\section{Introducción}

En la historia de la investigación comunicativa es y ha sido una constante la preocupación por delimitar las audiencias, saber quiénes son y, sobre todo, qué más son además de telespectadores, de datos estadísticos que sustentan tendencias de preferencias programáticas, horarios de exposición a los medios y perfiles (Orozco, 1996).

Si bien los planteamientos clásicos que predominaron como principales líneas de investigación sobre la recepción televisiva durante muchos años se centraron en el análisis de contenido y en la teoría de los efectos de la comunicación de masas, las nuevas demandas sociales de la investigación apuntan al rompimiento con la huella marcada por la historia del poder comunicativo, que a su vez se vincula con la historia de la investigación de la comunicación de masas y las líneas de estudio hasta hoy desarrolladas (De Moragas: 1981). A lo largo de la historia de la televisión en España "No sólo los medios cambian, los sujetos receptores también. Ambos se transforman y su apreciación dinámica se mantiene en continuo movimiento, lo que siempre constituye un desafío para la investigación en comunicación" (Orozco, 2002: 23).

El cambio en la concepción de receptores y audiencias como protagonistas del proceso comunicativo, comienza a fraguarse en el momento en que el mercado audiovisual y los gestores de la televisión constatan la importancia de conocer a todos aquellos que están detrás de la pantalla, aquellos quienes día a día mueven el negocio televisivo pasando así, aunque de forma paulatina y con reticencias, de una perspectiva puramente cuantitativa de su estudio a una cualitativa, mucho más centrada en la personalización de las audiencias.

Asimismo Internet, con su nuevo modelo interactivo-participativo, llegaría para transformar los procesos de comunicación de forma profunda, propiciando un cambio en el paradigma del sistema de comunicación unidireccional, imperante en los medios de comunicación, convirtiéndose en una plataforma de despegue para el surgimiento de un telespectador y un usuario de los medios cada vez más activo y más crítico.

De esta manera, las demandas actuales en el ámbito de la investigación de las audiencias apuntan a poner el foco de atención en los telespectadores desde su perspectiva como "ciudadanos" pero también, y debido a la influencia de Internet y de las nuevas tecnologías, en su sentido más amplio, es decir, como usuarios de los medios de comunicación.

Considerando el nuevo contexto audiovisual convergente y la influencia de los nuevos movimientos civiles, el determinar en qué medida los telespectadores de manera organizada afectan o pueden llegar a influir en el desarrollo de la televisión, comienza a convertirse en una necesidad inherente en el campo de la investigación de audiencias en la relación sociedad-medios. 


\subsection{Metodología}

Con el objetivo de identificar la cantidad de producción científica desarrollada en el ámbito de la recepción televisiva desde la perspectiva de la ciudadanía organizada (asociaciones, agrupaciones y similares) y su incidencia en la televisión, se llevará a cabo una revisión bibliográfica de los artículos que aparecen en tres de las bases de datos de revistas españolas más importantes en el campo de la comunicación: Dialnet, DICE e In-Recs, basándose en el título del artículo y su contenido.

Los resultados obtenidos permitirán hacer un análisis sobre la importancia y la pertinencia de incluir en la agenda de investigación de la recepción de las audiencias a la sociedad civil organizada. Asimismo esta revisión bibliográfica permitirá detallar con mayor precisión la situación actual de este campo de estudio en relación a la producción de publicaciones científicas en España.

\section{Aproximaciones teóricas sobre la recepción televisiva}

Durante la última década se ha visto que una buena parte de las investigaciones relacionadas con el problema de la influencia social y el impacto de los medios de comunicación ha vuelto a girar en torno a las teorías del canadiense Marshall McLuhan (Horrocks, 2004: 12-13), sintetizadas en frases muy influyentes en la mente de los estudiosos de la comunicación y que a lo largo de las últimas cuatro décadas han tenido ocupado al mundo: "la aldea global", "el medio es el mensaje" y "los medios como extensiones de nuestros sentidos y de nuestras funciones" (McLuhan y Bruce, 1991).

Tal vez sin una intención explícita esas ideas apuntalaron la tesis precedente de la omnipresencia de los medios de comunicación de masas, en lugar de considerarlos simples instrumentos tecnológicos de la comunicación que se agregaron a otros ya existentes, por lo que sus efectos sobre los diversos públicos se tendrían que analizar más de acuerdo con los contextos sociopolíticos concretos en que se desarrollan.

Es posible que la base de sus ideas se encuentre más centrada en una preocupación que inició su discusión de manera más temprana en Estados Unidos, en los años cuarenta, y que se refería a una inquietud más sociológica que psicológica y planteada desde el estructural-funcionalismo más que desde el conductismo.

Entonces la pregunta central era: ¿cómo se dan los procesos de comunicación en cada situación concreta y qué efectos e influencias tienen en los involucrados en el fenómeno? Berelson (1948) sintetizaba muy bien los descubrimientos que se lograron a partir de aquellas interrogantes afirmando que: "ciertos tipos de comunicación acerca de cierto tipo de asuntos, pre- sentados a cierto tipo de personas, en ciertas condiciones, originan cierto tipo de efectos" (Berelson, 1948: 172). 
Por aquellos años con el paradigma de Lasswell se trasplantó a la comunicación masiva un esquema que correspondía, propiamente, al modelo de comunicación interpersonal, es decir, como si el medio fuera una persona y el público otra; bajo ese principio se iniciaron estudios muy influyentes en por lo menos tres áreas del conocimiento: efectos, contenidos y audiencia. No obstante y pese a aquella postura psicológica inicial, las primeras investigaciones ponían de manifiesto las influencias mutuas de los contactos personales y grupales en los procesos de comunicación, de tal manera que pronto se desecharon las tesis conductistas de la omnipresencia de los medios (De Moragas, 1981: 40-45).

Con esto se dejaba de interpretar al público como una entidad amorfa, homogénea, pasiva y desorganizada, para iniciar la investigación de las relaciones entre comunicación, organización e influencia personal (Moragas, 1981: 47). En la medida en que la investigación empírica se realiza, los resultados van ponien- do a prueba hipótesis que obligan a reformular las teorías que venían sosteniendo "verdades" científicas, pero que paso a paso van siendo refutadas. De esta manera, se pasa de la idea de la omnipresencia de los medios a la idea de la interacción de los medios con el resto de las estructuras sociales.

Este enfoque abre el panorama de las corrientes y enriquece el conocimiento de los fenómenos de comunicación de masas en la medida en que diversas ciencias que se habían desarrollado suficientemente de manera autónoma, se ven atraídas por estos fenómenos que resultan de interés mayúsculo para ampliar su visión sobre la naturaleza de sus objetos de estudio originales. Se demuestra que en las sociedades "democráticas" el público selecciona su exposición a los medios de acuerdo con su línea, gustos e intereses.

La teoría que se construye a partir de estos descubrimientos invierte los intereses heurísticos de la ciencia de la comunicación. A partir de ese momento se quiso saber cuáles eran las condicionantes que el receptor impone al medio, y lo que el público hace con los medios y sus mensajes, en lugar de estudiar lo que los medios influyen en sus audiencias, invirtiendo la tendencia sobre las influencias entre ambos.

Immanuel Wallerstein advierte que en la posguerra las ciencias sociales empezaron a romper la camisa de fuerza del formalismo academicista que las obligaba a mantener una existencia separada unas de otras y, adaptándose a los problemas epistemológicos que ofrecía la realidad compleja, se abrieron a la práctica interdisciplinaria, de donde surgieron nuevos campos de investigación como el de las ciencias administrativas, las ciencias del comportamiento y el campo de estudios de la comunicación que se apoyó en la psicología, la sociología, la semiología, la ciencia política, la economía, la lingüística, etcétera (Wallerstein, 2003: 52).

Entre las posturas teóricas de la comunicación, aparentemente opuestas, pero cada vez más cercanas entre sí, a fines de los años sesenta se destaca un pensador alemán refugiado en Estados Unidos durante los primeros años de la Segunda Gue- rra Mundial, muy agudo e influyente en los movimientos estu- diantiles del 68: Herbert Marcuse, quien decía que los derechos y libertades que fueron factores vitales en los 
orígenes y etapas tempranas de la sociedad industrial, se debilitan en una etapa más alta de esta sociedad "perdiendo su racionalidad y contenido tradicionales" (Marcuse, 1973).

Marcuse (1973) ya había dejado ver en sus reflexiones el poder que se le confería a la televisión, preguntándose si realmente se podía diferenciar entre los medios de comunicación de masas como instrumentos de información y diversión, o como medios de manipulación y adoctrinamiento que diseñaban la vida del hombre en relación a su trabajo en la sociedad industrial como una forma predominante de control social. En esta misma línea, tal y como afirma Giovanni Sartori (1997), la televisión ha ido convirtiendo al homo sapiens, animal racional, en un homo videns, animal eminentemente simbólico, donde el telespectador se encuentra inmerso en una cultura predominantemente visual..

A partir del cambio de régimen político sufrido en España se vive un periodo de transición en donde los asuntos centralizados y controlados a nivel estatal comienzan a ser tratados desde los espacios de la sociedad civil, lo que Gramsci definía como "la sede donde se forma y transforma la cultura" (Habermas, 1998).

Desde esa perspectiva se desprende la importancia de promover una sociedad civil comprometida con su rol e informada sobre las cuestiones que le atañen; una sociedad crítica y participativa, ya que es en ella donde se pueden engendrar los grandes cambios sociales. Por su parte Habermas (1998: 8) sostenía que las instituciones, cuando funcionan correctamente, se convierten en un factor de primer orden en bien de la emancipación; de ahí la importancia del asociacionismo como una forma de implicación y compromiso social hacia la propia comunidad, que puede llegar a ser el cimiento de un movimiento que transforme las energías y cambie el rumbo de los acontecimientos en la mejora de alguna problemática común.

La esfera pública, según este autor, ya no se plantea como participación directa en el poder, sino como vigilancia y crítica desde la sociedad frente al poder, siendo ésta el lugar en el que se forma la opinión pública, o sea, la voz de la sociedad civil.

En esa esfera se moldean las ideas y los ideales, los valores y las expresiones culturales de la sociedad (1998: 9); es el espacio en el que los ciudadanos deliberan acerca de los asuntos comunes, cual ágora griega. Por otra parte, es también en la sociedad civil donde se generan los procesos de legitimación que sostienen la validez del poder político y brindan estabilidad a la actividad económica (Fernández Santillán, 2005: $15)$.

Bourdieu (1974) ofrece una visión sociológica de la estructura social en la que distingue los niveles superestructurales como campos de lucha ideológica que se entremezclan entre sí, en lo particular en el ámbito televisivo, en el que se consolidan y difunden las formas más dominantes de los grupos de poder; él lo define así: llamo campo a un espacio de juego, a un campo de relaciones objetivas entre los individuos o las instituciones que compiten por un juego idéntico [...] En un campo los que poseen la posición dominante, los que tienen más capital específico, se oponen en 
numerosos aspectos a los recién llega- dos, a los que llegaron tarde —en este caso a los telespectadores organizados-, los advenedizos que no poseen mucho capital específico (Bourdieu, 1974: 216).

Cabe hacer referencia que entre los factores que explican el declive de las sociedades participativas se encuentra, en palabras de Putnam (2000), la televisión, pues afirma que: "más tiempo frente al televisor significa la disminución prácticamente de toda forma de participación cívica y de compromiso social". Esto remarca la importancia de este estudio y de la trilogía: televisión, participación ciudadana y asociacionismo.

\subsection{El cambio de paradigma en la investigación de las audiencias de televisión}

Desde sus inicios el telespectador fue considerado simplemente un receptor, un individuo que se posaba frente a un televisor que recibía mensajes unidireccionales e imágenes para consumir a libre albedrío. En 1959, Katz (1973) fue uno de los primeros en proponer un enfoque distinto en esta materia, considerando que se debía prestar menos atención a lo que los medios hacían con la gente y más a lo que la gente hacía con los medios. Sin embargo, no sería hasta el año de 1973 con la teoría de usos y gratificaciones de Katz y Gurevich, cuando la investigación de las audiencias comenzaría a centrarse en los usos que hacen los telespectadores del contenido de los medios; estos autores identificaron cuatro tipo de necesidades que los telespectadores buscan satisfacer al momento de consumir los mensajes: integración a nivel social y personal, de evasión o de escape (diversión y entretenimiento), cognitivas (el deseo de estar informado) y afectivas-estéticas, relacionadas con el refuerzo de experiencias emocionales y de placer (Katz, 1973).

Ya entrada la década de los sesenta, el telespectador, concebido como masa, se convertiría en el primer punto de análisis en las investigaciones en esta materia. A partir de entonces, el enfoque de la investigación sobre la recepción televisiva comenzaría a experimentar un cambio que pasaría de una comprensión cuantitativa hacia una cualitativa del fenómeno, considerando que los receptores de los medios no eran ni tan homogéneos, ni tan pasivos, ni tan sumisos, y aceptando como relevo el concepto de audiencia para referirse a ellos (Castañares, 2008).

En 1979 Umberto Eco se cuestionó el papel activo del telespectador y su posible influencia sobre el medio en su libro ¿El público perjudica a la televisión? (De Moragas, 1981: 182). En él se planteaba la necesidad de contemplar al telespectador como un ente activo, formulando así una nueva dimensión dentro de la concepción tradicional del telespectador concebido como receptor.

Con esta idea se abriría una brecha para el estudio de las audiencias desde el punto de vista cualitativo, y de sus posibles efectos sobre los medios, un punto de vista que, sin lugar a duda, rompía con los paradigmas de su tiempo. Más adelante, las investigaciones sobre televisión parecerían iniciar un proceso de modernización que terminaría por romper el paradigma de la televisión como institución de dominio a 
través de la comunicación unidireccional de sus mensajes, para asumir la capacidad de acción y retroalimentación por parte de los telespectadores.

Hoy en día la entrada de la televisión digital y la multiplicación de canales han dado como resultado audiencias cada vez más diferenciadas y segmentadas. Ello sumado a las transformaciones en los procesos de comunicación que ha traído consigo Internet, está cambiando el escenario televisivo y el rol que hasta hace poco jugaba cada uno de los agentes involucrados. La cadena de valor del sector audiovisual se ha ido complejizando ante la entrada de nuevos agentes sociales; por una parte cabe destacar el protagonismo que en los últimos años han cobrado las empresas de telecomunicaciones, así como la función de telespectadores que ejercen un papel más activo como prosumers (productores y consumidores de contenidos audiovisuales y de información), pero que también se han vuelto cada vez más exigentes en lo que respecta a su consumo audiovisual, y reivindicativos en la defensa de sus derechos como ciudadanos.

Esto los ha llevado a involucrarse más activamente en los temas públicos y a conformar agrupaciones (asociaciones de telespectadores y observatorios de los medios), lo que da muestra del crecimiento del capital social de la televisión. "Un capital social entendido como el conjunto de redes sociales y normas asociativas de reciprocidad, que crean valor en términos individuales y colectivos" (Fernández-Santillán, 2005: 60). Estas transformaciones que se están produciendo en la relación entre los medios de comunicación y la inmersión de nuevos agentes sociales, sin lugar a duda constituyen una línea de estudio emergente en el campo de la comunicación, digna de ser analizada.

Asimismo, es evidente que ante la transformación de la cadena de valor de la televisión el rol del telespectador, también usuario de los nuevos medios, sufre una metamorfosis similar, consecuente con la evolución del medio. Hoy en día, el poder de los sujetos receptores como sujetos sociales forma parte de lo televisivo, por tanto su estudio, desde el punto de vista como ciudadanos usuarios de los medios, cobra mayor importancia.

\section{Análisis de las publicaciones científicas en bases de datos españolas}

Tras la revisión de las bases de datos españolas "Dialnet" que compila 7922 revistas; "Dice" (Difusión y Calidad Editorial de las Revistas Españolas de Humanidades y Ciencias Sociales y Jurídicas), y con base en el índice de impacto de las revistas españolas del área de ciencias sociales en la subárea de comunicación "In-Recs", el cual engloba a las revistas mejor posicionadas en esta área, que a su vez son unas de las mejores valoradas por la Agencia Nacional de Evaluación de la Calidad y Acreditación (ANECA), se ha podido constatar que existen muy pocos artículos publicados en revistas científicas que versen sobre la influencia de los telespectadores organiza- 
dos sobre la televisión, o de usuarios organizados que influyan en otros medios de comunicación, tal y como se aprecia en la siguiente tabla:

Tabla 1. "Artículos publicados en revistas españolas sobre el estudio de la influencia de los telespectadores sobre la televisión"

\begin{tabular}{|c|c|c|}
\hline Autor & Artículo & Revista \\
\hline Carmen Fuente Cobo & $\begin{array}{l}\text { "El papel del asociacionismo audiovisual } \\
\text { tras la LGCA. Las asociaciones de } \\
\text { usuarios de los medios como agentes de la } \\
\text { alfabetización mediática" }\end{array}$ & Icono 14 , núm. 14 \\
\hline Carmen Fuente Cobo & $\begin{array}{l}\text { "Ciudadanía activa y alfabetización } \\
\text { mediática. El papel de las asociaciones de } \\
\text { telespectadores y usuarios de los medios } \\
\text { en el nuevo escenario audiovisual" }\end{array}$ & $\begin{array}{l}\text { Comunicar. Revista } \\
\text { Científica Iberoamericana de } \\
\text { Comunicación y Educación, } \\
\text { núm. } 25 \text {. }\end{array}$ \\
\hline $\begin{array}{l}\text { María Jesús Fernández } \\
\text { Torres }\end{array}$ & $\begin{array}{l}\text { "La influencia de la televisión en los } \\
\text { hábitos de consumo del telespectador. } \\
\text { Dictamen de las asociaciones de } \\
\text { telespectadores" }\end{array}$ & Comunicar, núm. 25. \\
\hline Luis Boza Osuna & $\begin{array}{l}\text { "Las asociaciones de telespectadores en la } \\
\text { construcción de una televisión de calidad" }\end{array}$ & Comunicar, núm. 25. \\
\hline Luis Boza Osuna & $\begin{array}{l}\text { "Las asociaciones de telespectadores y } \\
\text { los derechos del menor en el panorama } \\
\text { audiovisual y multimedia" }\end{array}$ & $\begin{array}{l}\text { Libro: Psiconutrición del } \\
\text { menor }\end{array}$ \\
\hline Alejandro Perales Albert & $\begin{array}{l}\text { "La defensa de los derechos de la } \\
\text { ciudadanía en su relación con los medios } \\
\text { de comunicación. Un movimiento } \\
\text { emergente" }\end{array}$ & Contrastes. Revista Cultural \\
\hline Gloria Rosique Cedillo & $\begin{array}{l}\text { "Nuevos actores sociales en el escenario } \\
\text { audiovisual. Las asociaciones de } \\
\text { telespectadores" }\end{array}$ & Icono 14 , Vol. 5. $\mathrm{N}^{\mathrm{o}} 1$. \\
\hline Gloria Rosique Cedillo & $\begin{array}{l}\text { "Las asociaciones de telespectadores ante } \\
\text { el reto de la educación audiovisual" }\end{array}$ & Comunicar, núm 31. \\
\hline $\begin{array}{l}\text { Gloria Rosique Cedillo y } \\
\text { Francisco García García }\end{array}$ & $\begin{array}{l}\text { "El capital social de la televisión: el } \\
\text { movimiento asociativo de telespectadores } \\
\text { en España" }\end{array}$ & $\begin{array}{l}\text { Estudios sobre el Mensaje } \\
\text { Periodístico, núm } 17 .\end{array}$ \\
\hline Gloria Rosique Cedillo & $\begin{array}{l}\text { "Participación ciudadana y telespectadores: } \\
\text { hacia la construcción de una ciudadanía } \\
\text { audiovisual en España" }\end{array}$ & Razón y palabra, núm 58. \\
\hline Gloria Rosique Cedillo & $\begin{array}{l}\text { "El interés ciudadano por los contenidos: } \\
\text { los nuevos actores de la televisión" }\end{array}$ & Comunicar, núm. 25. \\
\hline
\end{tabular}

Fuente: Elaboración propia.

Los resultados anteriores dan muestra de la escasa producción científica en torno a esta línea de investigación, en comparación con la cantidad de artículos publicados 
acerca de la visión tradicional de la recepción televisiva, el análisis de contenido y sobre los efectos de la comunicación de masas.

Asimismo, los resultados permiten constatar que no hay una lógica entre el desarrollo del capital social de la televisión y la precaria producción científica sobre estos objetos de estudio, ya que actualmente sólo tres autores que se recogen en la Tabla 1 provienen del ámbito académico, por lo que el resto de los artículos que versan sobre esta temática han sido escritos por personas vinculadas al movimiento asociativo de telespectadores en España.

Finalmente cabe dejar constancia que además de las publicaciones mencionadas, se encontraron tres aportaciones relacionadas con la temática objeto de estudio, pero que correspondían a ponencias de congresos, siendo éstas de los autores anteriormente mencionados.

\section{Conclusiones}

Ante la fragmentación de las audiencias, el desarrollo de nuevas formas interactivas de comunicación multidireccional conver- gentes con Internet y la diversidad de soportes de visualización de imágenes e información, resulta obsoleto seguir hablando de audiencias, y más bien referirse de unos "usuarios de los medios" cada vez más próximos a su concepción jurídica como ciudadanos-telespectadores.

Desde la década de los ochenta y en el ámbito concreto de la televisión, vienen desarrollándose diversos grupos que han formado colectivos con una cierta organización, programas de acción, actividades y objetivos con un interés común: el de mejorar la calidad de la televisión en pro de la calidad de la ciudadanía y de hacer valer sus derechos.

El paso del telespectador como consumidor al de ciudadano, si bien es una línea de investigación poco desarrollada, en los últimos años comienza a cobrar más fuerza. Un ciudadano- telespectador cada vez más consciente del papel que juega como agente social en la estructura de poder de los medios, que no sólo se conforma con el poder de elegir productos culturales para su consumo, sino de exigir calidad en la búsqueda de su derecho a recibir información veraz y plural, así como contenidos éticos que cumplan con las normativas vigentes referentes a su regulación.

Asimismo, las nuevas demandas sociales, la opulencia infor- mativa y de imágenes están encauzando la investigación de la comunicación a analizar los fenómenos sociales transdisciplina- riamente, especialmente en el campo de la sociología y del dere- cho. Los más recientes conflictos sociales que tienen que ver con la estructura y el funcionamiento de la sociedad han dado lugar a lo que Dahrendorf (1979) denomina grupos de interés.

Debido al auge y al desarrollo de Internet estos grupos han cobrado protagonismo como agentes de cambio dentro de la estructura social. El Movimiento del $15 \mathrm{~m}$ o el 
Movimiento anti-Bolonia son ejemplos de cómo las redes sociales que se fraguan en el ciberespacio, han coadyuvado a la organización de grupos de interés que actualmente se conforman como sujetos de cambio de las estructuras sociales. Si bien Baudrillard (1991) partía de la idea de que "el poder es lo que no puede devolverse, o más exactamente, el poder es de aquel que puede dar y a quien no puede ser devuelto", hoy Internet ha hecho posible que la voz de los ciudadanos pueda ser escuchada en los dos sentidos de la comunicación, pese a los anteriores intentos de la televisión por dar la palabra a los telespectadores en los programas de televisión.

El desarrollo de Internet ha coadyuvado a la construcción de la ciudadanía audiovisual digna de ser analizada desde las distintas disciplinas del campo de las ciencias sociales. Tal como señala Martín-Barbero (1998): "el tejido de la democracia se hace comunicativamente y ese tejido cada vez más se realiza frente, no detrás de los medios". Por tanto, es necesario revisar y redimensionar la investigación de las llamadas audiencias desde el punto de vista sociológico-jurídico, como grupos organizados y a su vez como defensores de sus derechos como ciudadanos inmersos en una cultura audiovisual. Unos ciudadanos polivalentes de los medios que no han dejado de ser telespectadores para formar parte del mundo de internet y que, como usuarios, de manera aislada o a través de sus manifesta- ciones colectivas, merecen la atención de los estudios en este campo.

Pese a la prolífica investigación que se ha llevado a cabo en relación a los diversos objetos de estudio en el campo televisivo, la revisión bibliográfica realizada en las principales bases de datos de revistas españolas del área de la comunicación, hacen constatar que el número de artículos académicos especializados en el estudio de la influencia de los telespectadores o usuarios de los medios sobre la televisión, sigue siendo incipiente.

No obstante, cabe destacar que la importancia del estudio de esta línea de investigación radica en el acercamiento al complejo panorama televisivo, en relación a la participación ciudadana de los grupos organizados, principalmente en asociaciones de telespectadores, que promueven una cultura ciudadana, donde el punto central radica en conocer los canales o las vías reales que tiene el ciudadano para participar y hacer llegar su voz, y por ende, incidir en el medio.

Estos grupos civiles empujan al fortalecimiento de un debilitado capital social y a su construcción; este capital social es el que precisamente resulta más importante desarrollar, toda vez que el capital humano y el capital físico son factores ya existentes en el campo de la televisión como parte del proceso lógico para integrar los elementos técnicos, materiales y humanos que hicieron posible la prehistoria de este medio. En el libro clásico de Almond y Verba "Civic Culture" (1989), Alexis de Toqueville destaca que lo que el capital social aporta es la posibilidad de convertir los problemas individuales en colectivos, teniendo como base a los grupos organizados desde el seno de lo civil, quienes unen sus intereses para mejorar algún aspecto que repercute a toda la comunidad. 
Es precisamente aquí donde radica la importancia de estudiar a los grupos civiles organizados como nuevos agentes sociales, partícipes en el sector audiovisual y, desde la academia poner el foco de atención en el estudio, actividad y desarrollo de estas nuevas manifestaciones sociales emergentes.

\section{Referencias bibliográficas}

AlMond A. G.; VERBA, S. (1989). The Civic Culture. Political Attitudes and Democracy in Five Nations. California: Sage.

BAUDRILLARD, J. (1991). Crítica de la economía política del signo. México: Siglo XXI.

BERELSON, B. (1948). "Communications and Public Opinions”. En SCHRAMM, W. (1948). Communication in Modern Society. Chicago: Illinois University Press. BORDIEU, P. (1974). Campo del poder y campo intelectual. Buenos Aires: Folios.

DAHRENDORF, R. (1979). Las clases sociales y su conflicto en la sociedad industrial. Madrid: Rialp.

DE MORAGAS SPÀ, M. (1981). Teorías de la comunicación: investigaciones sobre medios en América y Europa. México: Gustavo Gili.

DEBORD, G. (1990). Comentarios sobre la sociedad del espectáculo. Barcelona: Anagrama.

FERNÁNDEZ SANTILLÁN, J. (2005). Sociedad civil: cultura política y cultura ciudadana. México: Concepción Haydee Rojas Barradas.

HABERMAS, J. (1998). The Structural Transformation of the Public Sphere. Massachusetts: Mit Press.

HORROCKS, Ch. (2004). Marshall McLuhan y la realidad virtual. Barcelona: Gedisa.

KATZ, E.; GUREVITCH, M.; HADASSAH, H. (1973). On the Use of the Mass Media for Important Things. Philadelphia: University of Pennsylvania.

MARCUSE, H. (1973). El hombre unidimensional. México: Joaquín Mortiz.

MARTÍN-BARBERO, J. (1998). De los medios a las mediaciones: comunicación, cultura y hegemonía. Barcelona: Gustavo Gili.

MCLUHAN, M.; BRUCE, R. P. (1991). La aldea global: transformaciones en la vida y los medios de comunicación mundiales en el siglo XX. Barcelona: Gedisa.

OROZCO GÓMEZ, G. (1996). Televisión y audiencias: un enfoque cualitativo. Madrid: De la Torre.

OROZCO GÓMEZ, G. (2002). “Travesías de la recepción en América Latina”. En OROZCO GÓMEZ, G. (coord.) (2002). Recepción y mediaciones: Casos de investigación en América Latina. Buenos Aires: Norma. pp. 162.

PUTNAM, R. (2000). Bowling Alone (The Collapse and Revival of American Community). Nueva York: Simon and Schuster.

SARTORI, G. (1997). Homo videns. Madrid: Taurus.

WALLERSTEIN, I. (2003). Después del liberalismo. México: Siglo XXI y Centro de Investigaciones Interdisciplinarias en Ciencias y Humanidades,UNAM. 


\section{Referencias electrónicas}

CASTAÑARES, W. (2008): "La investigación de los nuevos receptores: categorías y procedimientos". En Congreso Internacional Fundacional de la AE-IC. Disponible en: www.aeic.org/santiago2008/contents/pdf/comunicaciones/249.pdf. Fecha de consulta: [04-02-2013].

\section{La autora}

Doctora Europea en Ciencias de la Información por la Universidad Complutense de Madrid y Máster en Dirección de la Empresa Audiovisual por la Universidad Carlos III. Profesora en el departamento de Periodismo y Comunicación Audiovisual de la Universidad Carlos III de Madrid.

Autora de una veintena de artículos, capítulos de libro y participación en congresos nacionales e internacionales sobre recepción televisiva y el movimiento asociativo de telespectadores; contenidos de TV y grupos de comunicación; el EEES y metodologías docentes.

Miembro del Consejo de Redacción de la revista Global Media Journal (GMJE) y pertenencia al Sistema Nacional de Investigadores de México (SNI). 